\title{
The Influence of the Comprehensive Second Child Policy on China's Population
}

\author{
Han $\mathrm{Li}^{1, \mathrm{a}}$, Yi Cheng ${ }^{2, \mathrm{~b}^{*}}$, Bingjun $\mathrm{He}^{2, \mathrm{c}}$ and Shi Kang ${ }^{2, \mathrm{~d}}$ \\ 1 Department of Mathematics, Bohai University, Jinzhou121013, China \\ 2College of Mathematics and Physics, Bohai University, Jinzhou121013, China \\ a15566527260@163.com, b chengyi407@126.com, \\ c 362360915@qq.com, d2367230337@qq. \\ *The Corresponding author
}

Keywords: Rate of female birth rate; Couple fertility; Survival rate; Whitening background value of grey derivative

\begin{abstract}
China's current population problems, is the introduction of the second child policy. In this paper, we evaluate the influence of the comprehensive second child policy on China's population. We first establish the appropriated evaluation index system, and then through the establishment of mathematical models we make a prediction and quantitatively compare the influence of China's population before and after the implementation of the second child policy. At the same time, according to the results of this study, from the perspective of government decision - making, we further put forward some rationalization proposals on the means of supporting. Our research shows that the implementation of the child policy has a mitigating effect on the growing aging population. The problem of labor shortage has been solved to some degree to promote the development of economy. The model has high practicability, and accurate data is given to analyze the problem from multiple angles.
\end{abstract}

\section{Establishing Suitable Evaluation Index System and the Mathematical Model to Show the Impact of the Comprehensive Second Child Policy on the Population of China}

China is a populous country, population development is a major problem plaguing our country. Nowadays, China is facing many population problems, such as acceleration of population ageing process, sustained increase in the gender ratio of the population and so on. To quantify the impact of the comprehensive second child policy on China's population, we analyze the female fertility and aging of population objectively, evaluate comprehensively the demographic changes, to gain the influence of the comprehensive second child policy on the population of China. We use the total population of China as an evaluation indicator, to figure up the influence of the second child policy on the Chinese population.

\section{Symbols and Their Meanings}

$\mathrm{m}_{\mathrm{i}}(\mathrm{k})$-----Total number of women in "i" age group and " $\mathrm{k}$ ” year. $(\mathrm{i}=0,1,2 \ldots \mathrm{n})$

$\mathrm{p}_{\mathrm{i}}(\mathrm{k})$-----Rate of female birth rate in "i" age group and " $\mathrm{k}$ " year.

$\mathrm{q}_{\mathrm{i}}(\mathrm{k})$----Female mortality rate in " $\mathrm{i}$ " age group and " $\mathrm{k}$ " year.

$\mathrm{c}_{\mathrm{i}}(\mathrm{k})$----Female survival rate in "i”" age group and " $\mathrm{k}$ " year.

$\mathrm{x}(\mathrm{k})$----Proportion of women born in the " $\mathrm{k}$ " year.

Build the Following Sodium Calculate Formula

$$
\begin{aligned}
& m_{1}(k+1)=\sum_{i=1}^{n} p_{i} m_{i}(k) x(k) \\
& m_{i+1}(k+1)=c_{i} m_{i}(k)(\mathrm{i}=0,1,2 \ldots \mathrm{n}),
\end{aligned}
$$

this is written in matrix form 
$m(k+1)=\operatorname{Lm}(k)$

where

$$
L=\left(\begin{array}{ccccc}
x p_{1} & x p_{2} & \cdots & x p_{n-1} & x p_{n} \\
c_{1} & 0 & \cdots & \cdots & 0 \\
0 & c_{2} & 0 & \cdots & \cdots \\
\cdots & \cdots & \cdots & 0 & \cdots \\
0 & \cdots & 0 & c_{n-1} & 0
\end{array}\right)
$$

Then

$$
m(k+1)=\left(\begin{array}{c}
m_{0}(k+1) \\
m_{1}(k+1) \\
\cdots \\
m_{n-1}(k+1) \\
m_{n}(k+1)
\end{array}\right)=\left(\begin{array}{ccccc}
x p_{1} & x p_{2} & \cdots & x p_{n-1} & x p_{n} \\
c_{1} & 0 & \cdots & \cdots & 0 \\
0 & c_{2} & 0 & \cdots & \cdots \\
\cdots & \cdots & \cdots & 0 & \cdots \\
0 & \cdots & 0 & c_{n-1} & 0
\end{array}\right) \cdot\left(\begin{array}{c}
m_{0}(k) \\
m_{1}(k) \\
\cdots \\
m_{n-1}(k) \\
m_{n}(k)
\end{array}\right)=\operatorname{Lm}(k)
$$

By Eq.5, it follows that

$$
m(k)=L^{(k)} m(0) \text {. }
$$

Based on " $L$ " matrix and initial female population distribution vector" $m_{0}$ ", we get the distribution of the female population in " $k$ " year. The indicators of the total population are extrapolated through the proportion of men and women.

Calculation of Future Population. Thought the sixth time nationwide census in 2010, we have the female fertility and survival rate in all ages which is given by the following.

Female fertility.

$\mathrm{P}=[0,0,0,0.03085,0.43575,0.4779,0.25615,0.09875,0.03715,0.0281,0,0,0,0,0,0,0,0,0,0,0]$

Survival rate.

$\mathrm{c}=[0.9987106,0.9996988,0.9997009,0.9996099,09994898,0.9993782,0.9992037,0.99883,0.9982$ $38,0.9972979,0.9957842,0.9938143,0.989688,0.9827936,0.9694003,0.9503787,0.9151438,0.87054$ $74,0.8094176,0.7828964,0.545615]$

Data on the specific gravity of new born baby girls from 2009 to 2016.

$\mathrm{x}=[0.47826087,0.48076923,0.46889952,0.47393364,0.464114833,0.465116279$, 0.460829493]

Proportion of female infants is

$$
\bar{x}=\left(x_{1}+x_{2}+x_{3}+x_{4}+x_{5}+x_{6}+x_{7}\right) / 7=0.470274839 \text {. }
$$

Bring the data into the equation, getting the number of women in the second year.

$$
m(1)=\left(\begin{array}{c}
m_{1}(1) \\
m_{2}(1) \\
\cdots \\
m_{20}(1) \\
m_{21}(1)
\end{array}\right)=\left(\begin{array}{ccccc}
\bar{x} p_{1} & \bar{x} p_{2} & \cdots & \bar{x} p_{20} & \bar{x} p_{21} \\
c_{1} & 0 & \cdots & \cdots & 0 \\
0 & c_{2} & 0 & \cdots & \ldots \\
\cdots & \cdots & \cdots & 0 & \ldots \\
0 & \cdots & 0 & c_{20} & 0
\end{array}\right) \cdot\left(\begin{array}{c}
m_{1}(0) \\
m_{2}(0) \\
\ldots \\
m_{20}(0) \\
m_{21}(0)
\end{array}\right)=\operatorname{Lm}(0) .
$$

By continuous iterative computation, we budget out of population structure in 2015, 2020, $2025 \ldots 2055$ which is shown in the following table. 


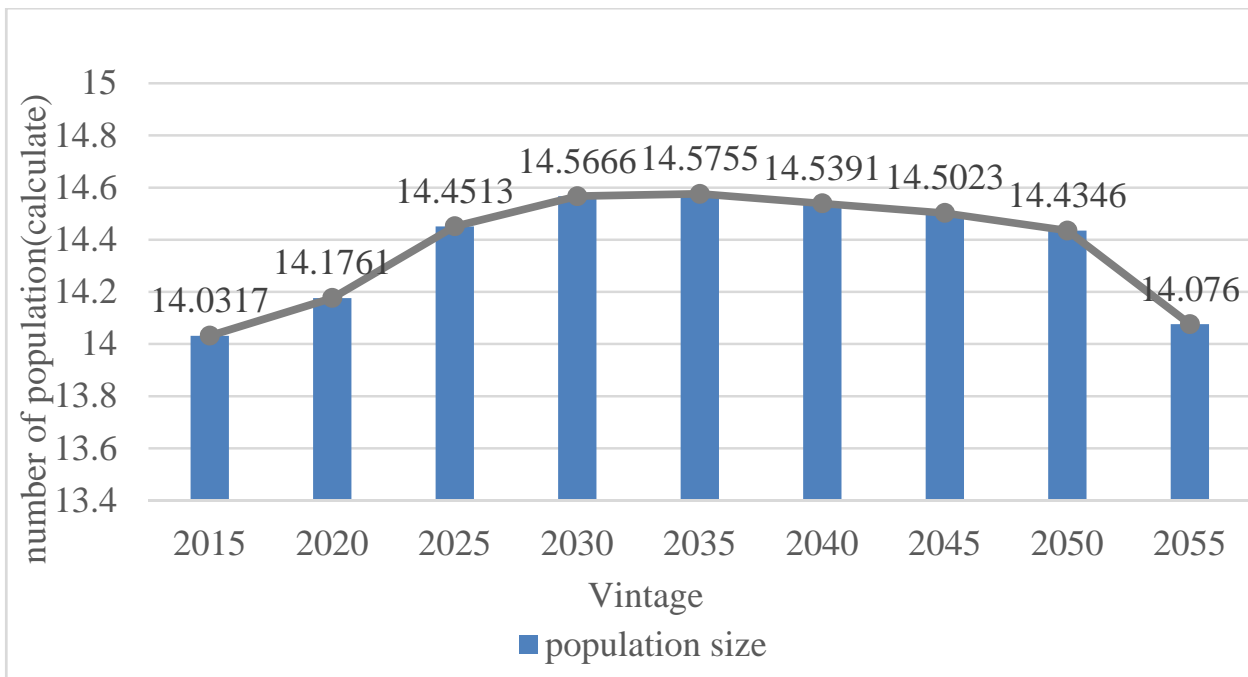

Figure 1. The population from 2015 to 2055

Using the Mathematical Model above, we Forecast the Impact of China's Population before and after the Implementation of the Second Child Policy

In recent years, with the development of China, China faces new challenges of population problems. According to the displaying data, the trend of aging problem in China is easy to see. The implementation of the second child policy would have a huge impact on the population of China. So we collected the relevant data, establishment of suitable evaluation index system and build a mathematical model for exploring the impact of the comprehensive second child policy on China's population.

\section{Mathematical Model}

The model is a variable corresponding to the second order equation based on grey model, a dynamic model consisting of differential equations

$y^{(1)}+a z^{(1)}(t)=u, t=1,2, \cdots, n$

Where $\mathrm{y}^{(0)}$ is the original time series

$y^{(0)}=\left\{y^{(0)}(1), y^{(0)}(2), \cdots, y^{(0)}(n)\right\}$.

So a cumulative number of corresponding $\mathrm{y}^{(0)}$ is

$\left\{y^{(0)}(1), y^{(0)}(2), \cdots, y^{(0)}(n)\right\}$.

The sequence corresponding to the grey derivative is

$y^{(1)}(v)=\sum_{i=1}^{v} y^{(0)}(i)(v=1,2, \cdots, n)$.

The corresponding ash derivative is

$d(v)=y^{(0)}(v)-y^{(1)}(v-1)$.

The grey derivative of adjacent sequence in mean way is

$z^{(1)}(v)=\frac{1}{2}\left\{y^{(1)}(v)+y^{(1)}(v-1)\right\}, v=(2,3, \cdots, n)$.

And its partial sequence is

$z^{(1)}(v)=\left\{z^{(1)}(2), z^{(1)}(3), \cdots, z^{(1)}(n)\right\}$. 
Generalizing the above equations, we can derive that it satisfies the differential equation of the grey prediction

$d(v)+a z^{(1)}(v)=b$.

Here, $a$----Development coefficient, $z^{(1)}(v)$----Whitening backing value of grey derivative, $b$----Ash amount action.

Bring $v=2,3$, $\mathrm{n}$ into Eq.16, respectively.

$\left\{\begin{array}{c}y^{(0)}(2)+a z^{(1)}(2)=b \\ y^{(0)}(3)+a z^{(1)}(3)=b \\ \vdots \\ y^{(0)}(n)+a z^{(1)}(n)=b\end{array}\right.$

Let

$b=\left\{\begin{array}{cc}-z^{(1)}(2) & 1 \\ -z^{(1)}(3) & 1 \\ \vdots & \vdots \\ -z^{(1)}(n) & 1\end{array}\right.$

$Y=\left\{y^{(0)}(2), y^{(0)}(3), \cdots, y^{(0)}(n)\right\}^{T}, u=(a, b)^{T}$,

Eq.17 can be simplified the following

$Y=B u$.

The least square estimation method can be used. Let

$u=\left(B^{T} B\right)^{-1} B^{T} Y$.

The parameters are estimated. Let

$y^{(1)}=\frac{u}{a}=w$

be put into the following

$y^{(1)}(v)=\sum_{i=1}^{v} y^{(0)}(i)(v=1,2, \cdots, n)$.

Get its whitening form, that is,

$\frac{d w}{w}=-a d t$.

By variable separation method, we have

$w=l e^{-a}$ ("l" is constant).

From the initial value

$y^{1}\left(t_{0}\right)=y^{0}(1)$.

Therefore,

$l=\left(y^{(0)}(1)-\frac{u}{a}\right) e^{-a t}$. 
So

$\hat{y}^{(1)}(t)=\left[\left\{y^{(0)}(1)-\frac{u}{a}\right\}\right] e^{-a t}+\frac{u}{a}$.

And time response function of

$$
Y=\left\{y^{(0)}(2), y^{(0)}(3), \cdots, y^{(0)}(n)\right\}^{T}, u=(a, b)^{T}
$$

For the model, we discrete Eq.28 and obtain

$$
\hat{y}^{(1)}(v+1)=\left[y^{(0)}(1)-\frac{u}{a}\right] e^{-a t}+\frac{u}{a}
$$

Prediction of weary generation for sequence is given by

$$
\hat{y}^{(1)}(v+1)
$$

$$
\hat{y}^{(0)}(v+1)=\hat{y}^{(1)}(v+1)-\hat{y}^{(1)}(v)=\left[\left\{y^{(0)}(1)-\frac{u}{a}\right\}\right]\left(1-e^{a}\right) e^{-a v}, v=1,2, \cdots, n, n+1, \cdots
$$

The concrete formula for prediction is obtained.

Computational Analysis Data. According to the past number and proportion of over 65 years old in China, the Number and Proportion of old person from 2014 to 2020 shown in the following table is predicted by GM(1.1) model.

Table 1 Data on ageing population from 2009 to 2016

\begin{tabular}{|l|l|l|}
\hline Vintage & $\begin{array}{l}\text { Aging population } \\
\text { [ten thousand] }\end{array}$ & $\begin{array}{l}\text { Specific gravity of the } \\
\text { aging population[\%] }\end{array}$ \\
\hline 2005 & 95.6 & 14.78 \\
\hline 2006 & 98.4 & 15.19 \\
\hline 2007 & 103.3 & 15.67 \\
\hline 2008 & 107.1 & 16.45 \\
\hline 2009 & 111.3 & 17.21 \\
\hline 2010 & 115.8 & 18.33 \\
\hline 2011 & 119.4 & 19.35 \\
\hline 2012 & 128.9 & 20.01 \\
\hline 2013 & 130.1 & 20.54 \\
\hline 2014 & 134.2 & 20.65 \\
\hline 2015 & 143.5 & 20.88 \\
\hline
\end{tabular}

The above data is taken into the“Eq.33" and we put the value of the $v$ from 0 to 16 into it. Then

$$
\hat{y}^{(0)}(v+1)=\hat{y}^{(1)}(v+1)-\hat{y}^{(1)}(v)=\left[\left\{y^{(0)}(1)-\frac{u}{a}\right\}\right]\left(1-e^{a}\right) e^{-a v}, v=1,2, \cdots, n, n+1, \cdots
$$

We forecast of the proportion of the aged population in the absence of the second child policy from 2014 to 2020.

For the same reason, we also forecast of the proportion of the aged population under the second child policy from 2014 to 2020. 


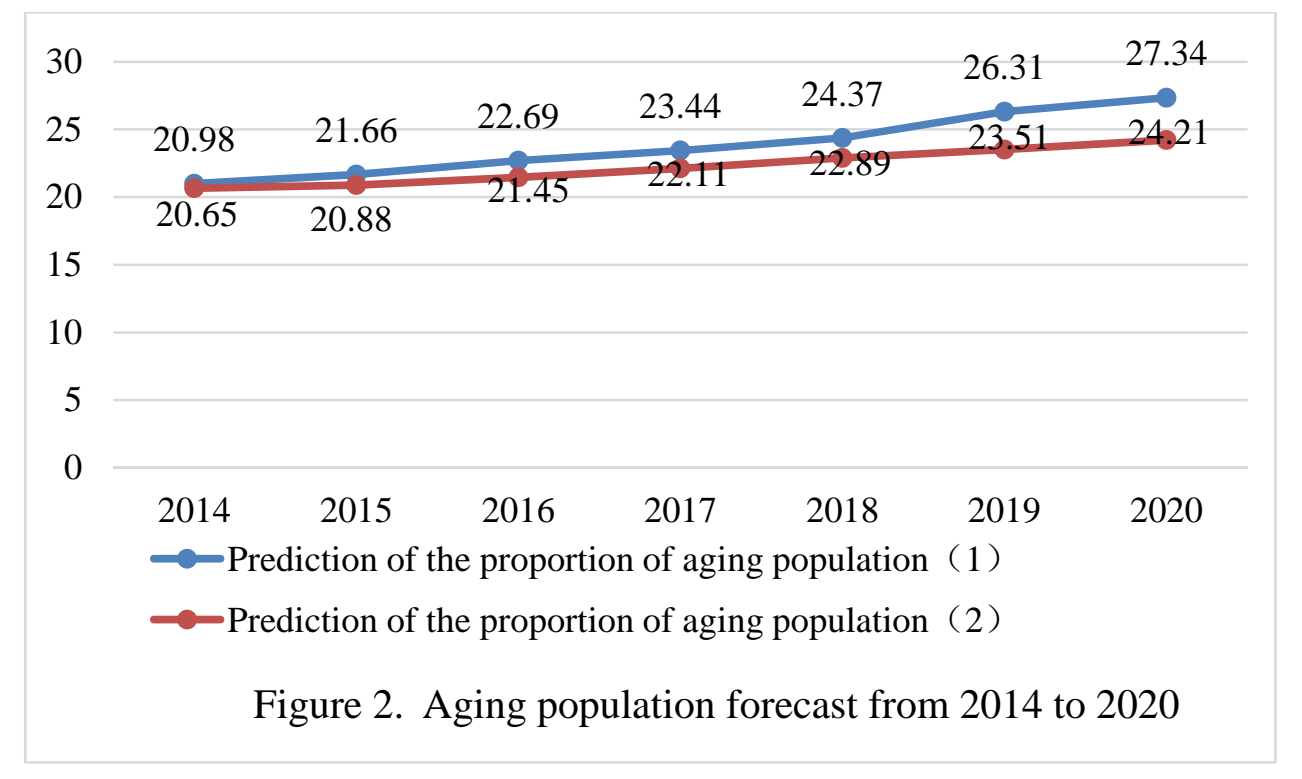

From the above graphic, we show that the implementation of the second child policy has a mitigating effect on the growing aging population. The implementation of this policy would increase the supply of labor, and promote the development of economy.

\section{Suggestions on the Implementation of the Comprehensive Second Child Policy}

From the perspective of government decision--- making, we base on the results of previous studies, and give some suggestions on the implementation of the second child policy, to make the development of population in line with the progress of society.

First of all, reforming the old - age pension system and reducing the cost of raising children are important. Secondly, we should promote the aging industry and perfect the endowment insurance system. Another suggestion is to achieve free entrance to school and try to train technical personnel. Finally we will deepen reform of the medical and health system and ensure the people's access to basic health care.

\section{Reference}

[1]H.G. Xie: The People's Republic of China Statistical Bulletin on National Economic and Social Development (National Bureau of Statistics, China 2012), p.238.

[2]X.Y. Wang: A review of the study on the aging of Chinese population, (1990) No.5, p.47.

[3]Q.Y. Jiang and J.X. Xie: Selected case selection of mathematical modeling (Higher Education Press, China 2006), p.63.

[4]Y.S. Ling: Model selection and parameter determination in population prediction (Science of finance and economics, China 2004), p.492.

[5]X.Y. Zhang: MATLAB software and mathematical experiments (China University of Mining and Technology, China 2000), p.4.

[6]G.Y. Yang: Mathematical modeling (China University of Technology, China 2008), p.43.

[7]J.N. Yang: Introduction to western development economics (Tian jin people press, China 1988), p.600.

[8]P.F. Song: A comparative study of population prediction methods in English translation population prediction methods (Ph.D., University of Anhui, China 2013), p.23.

[9]X.Q. Han: A simulation study of China's future population strategy based on Leslie model (Ph.D., Dong bei University of Finance and Economics, China 2012), p.12.

[10]C.H. Yin and L. Chen: Research and application of population prediction model based on BP neural network, (2005) No.2, p91. 